\title{
O POSICIONAMENTO DE COMUNICAÇÃO DO VAREJO REGIONAL DIANTE DO CRESCIMENTO DO E-COMMERCE: O CASO DA ENY ${ }^{1}$
}

\author{
Kauan Prates Gonçalves ${ }^{2}$ \\ Ângela Cristina Trevisan Felippi ${ }^{3}$
}

\begin{abstract}
RESUMO
Os processos de globalização associados à revolução digital fizeram nascer novas formas de oferta e de consumo de produtos em distintas escalas. Uma delas foi o e-commerce, que surgiu e se desenvolveu a ponto de provocar movimentos de adesão à venda eletrônica por parte do comércio tradicional ou de busca de alternativas para suportar a concorrência que assim se coloca. $\mathrm{O}$ artigo traz os resultados de uma pesquisa que buscou compreender o posicionamento de comunicação de uma quase centenária rede de comércio varejista de calçados da região Central do Rio Grande do Sul, Brasil, diante do avanço do e-commerce empreendido por empresas globais do setor. Valeu-se de pesquisa bibliográfica, documental e entrevistas com dirigentes e profissionais do setor de comunicação da rede regional. Movimentou-se pela discussão conceitual sobre território, comunicação estratégica e posicionamento de comunicação, centrando-se na análise desse último na empresa em estudo, entendido como uma reação aos movimentos do e-commerce. Identificou um posicionamento centrado na valorização do vínculo da referida empresa com o território, materializado na relação direta com os consumidores, na confiança mútua e na transparência.
\end{abstract}

Palavras chave: Posicionamento de comunicação. Comércio varejista. E-commerce. Desenvolvimento regional.

\footnotetext{
${ }^{1} \mathrm{Na}$ sua primeira versão, este estudo foi apresentado no III SEDRES, realizado de 14 a 16 de setembro de 2016, na cidade de Blumenau (SC).

${ }^{2}$ Mestre em Desenvolvimento Regional pelo Programa de Pós-Graduação em Desenvolvimento Regional da Universidade de Santa Cruz do Sul (UNISC). Publicitário e Relações Públicas. Santa Cruz do Sul, Rio Grande do Sul, Brasil. kauanpg@ hotmail.com

${ }^{3}$ Professora do Programa de Pós-Graduação em Desenvolvimento Regional (PPGDR) da Universidade de Santa Cruz do Sul (UNISC). Líder do grupo de pesquisa do CNPq Desenvolvimento Regional e Processos Socioculturais. Santa Cruz do Sul, Rio Grande do Sul, Brasil E-mail: angelafe@ unisc.br.
} 


\title{
THE REGIONAL RETAILER COMMUNICATION POSITIONING IN FACE OF E- COMMERCE: THE CASE OF THE ENY
}

\begin{abstract}
The globalization process combined with the digital revolution created new forms of supply and demand for consumer products. One of them was the e-commerce, which grew to the point of provoking traditional retailers to take initiatives to join it or to search for alternatives to counteract the arising competition. This article brings the results of a research aimed at understanding the communication positioning of an almost centenary regional shoe chain store located in the central region of Rio Grande do Sul state, Brazil, and their efforts to stand up in face of the growing e-commerce by global competitors. We used bibliographic and documental research and interviews with communication managers and consultants of the regional chain stores. We continued with a conceptual discussion about territory, strategic communication and communication positioning, focusing on the analysis of the latter on our subject of study from the standpoint of a counteraction to the e-commerce movements. We identified a positioning centered on the valuation of the bonds with the territory materialized in direct relationships with the consumers, mutual trust and transparency.
\end{abstract}

Keywords: Communication Positioning. Retail trade. E-commerce. Regional development.

\section{INTRODUÇÃO}

As interações das pessoas com informações, culturas e mercadorias de distintos lugares do planeta foram alteradas com a revolução digital do final do século XX, a partir do advento de novas tecnologias de informação e comunicação, associadas à expansão o capital, acarretando a mundialização de marcas e de consumidores (ORTIZ, 1994). Santos (2006) percebe que as mudanças ocorridas com a expansão do capitalismo possibilitaram o aumento de trocas intercontinentais de produtos e de culturas, fazendo com que os consumidores ficassem mais expostos às marcas e ofertas globais. Desta forma, o poder de compra e de consumo sai das escalas local, regional ou mesmo nacional e parte para um âmbito global, por meio dessa desterritorialização de produtos e marcas.

Para além da chegada de produtos globais por meio de pontos físicos de vendas, a internet se coloca como um novo meio de pesquisa para a decisão de compra, ao menos por uma parcela dos consumidores com acesso à rede, que encontra um universo de escolha de produtos e marcas muito maior do que no comércio tradicional. $\mathrm{O}$ e-commerce caracteriza-se como uma forma de compra e venda diferente das tradicionais. Por meio dele, os consumidores passam de um número restrito de empresas fisicamente acessadas e um volume e variedade de produtos limitados ao estoque físico das mesmas, para o acesso a uma gama muito maior de empresas e produtos geralmente com preços mais competitivos e facilidades.

Dados do Governo Federal sobre compras pela internet (E-COMMERCE, 2015) apontam que, no ano 2000, cerca de cinco milhões de pessoas já haviam utilizado, pelo menos uma vez, esta prática de compra no Brasil. Atualmente, o País é o quinto que mais comercializa produtos neste meio, ficando atrás apenas da China, que vem em primeiro lugar 
com mais de 538 milhões de pessoas que já utilizaram o e-commerce, seguida por Estados Unidos, Índia e Japão. No ano de 2014, o e-commerce girou mais 35,8 bilhões de reais no Brasil e, no ano de 2015 esse número superou os 43 bilhões de reais (E-COMMERCE, 2015).

Em contrapartida a este acesso a produtos e ofertas que a internet possibilita, boa parte oriunda de empresas desterritorializadas, pode-se perceber que ainda há valor simbólico agregado em empresas com vínculo territorial em distintas escalas e com comércio tradicional, mesmo que as mesmas também pratiquem o e-commerce. Sentidos de confiança, afeição e proximidade com a marca se mantém, são usados pelas empresas tradicionais e disputam a adesão dos consumidores com outras estratégias de venda colocadas pelo $e$ commerce, geralmente calcadas em preço, comodidade na compra e variedade do estoque.

Este artigo se propõe a apresentar um estudo feito sobre o posicionamento de comunicação da Eny Comércio de Calçados LTDA diante do avanço do e-commerce. $\mathrm{O}$ objetivo foi conhecer a estratégia de comunicação da Eny a partir de indicativos de mudança na mesma em decorrência da concorrência com o e-commerce. Assim, buscou-se perceber de que forma a empresa Eny se posicionou comunicacionalmente diante da inserção dos concorrentes virtuais na região. O posicionamento está relacionado à imagem da marca projetada junto aos consumidores potenciais, calcada na identidade da marca ou da organização ao longo de sua existência. O posicionamento pode ser modificado, a partir de uma nova conjuntura que o exija, ou pode ser mantido e reforçado, por meio do planejamento estratégico de marketing e de comunicação e de consequentes ações de marketing e de comunicação. No artigo, analisam-se as ações de comunicação para se compreender qual o posicionamento da marca Eny frente às ameaças do $e$-commerce.

A Eny surgiu na cidade de Santa Maria, Rio Grande do Sul, Brasil, no ano de 1925. De uma primeira loja, nas décadas seguintes surgiram outras, segmentadas por faixa de público, operando em rede e se expandindo para outras cidades. A Eny comercializa hoje cerca de um milhão de pares de calçados por ano, movimentando a economia regional através de 600 fornecedores diretos e uma equipe de mais de 200 funcionários. As Lojas Eny, como são conhecidas, estão fisicamente em quatro cidades do Rio Grande do Sul, com 11 estabelecimentos em Santa Maria, região Central do Estado, e uma em Santa Cruz do Sul, uma em Cachoeirinha e uma em Porto Alegre. O estudo centra-se nas lojas de Santa Maria, município com aproximadamente 240 mil habitantes que atrai pessoas da região e de outras, especialmente, pelo comércio e serviços que oferta, com destaque para o comércio varejista e os serviços de saúde e de ensino.

O estudo se vale de pesquisa bibliográfica, documental e entrevistas. Para a análise do posicionamento foi adotado o modelo de Ries e Trout (1989), exposto na sequência do artigo, cujo modelo é composto de três etapas, sendo elas o objetivo da estratégia de comunicação, o diferencial da estratégia e sua a vantagem diante da concorrência. $\mathrm{O}$ artigo inicialmente enfrenta a questão teórica, fazendo discussão conceitual. Após, apresenta os passos metodológicos das pesquisa, a análise para, posteriormente, realizar uma síntese das conclusões. 


\section{GLOBALIZAÇÃO, E-COMMERCE E TERRITÓRIO}

O território é a incorporação e a apropriação do espaço pela ação social de diferentes atores (FLORES, 2015). Santos (2006), por sua vez, aproxima-se da ideia de um espaço em que a interação com os setores econômicos se faz presente neste processo, no qual o território utilizado é constituído como um todo complexo em que se entrelaça uma trama de relações conflituosas e também complementares. O autor compreende território como um recurso de garantia da realização de interesses particulares, e, ao mesmo tempo, um espaço para se recriarem estratégias de garantia da sobrevivência nos lugares. Santos também considera as empresas como integrantes do território, uma vez que possuem suas raízes e seu mercado consumidor nele. Relacionada a essa concepção de território, Haesbaert (2010) propõe entender região como um recorte do espaço geográfico definido por divisões espaciais, culturais, privadas e outras.

Os anos 70 são o marco temporal do início de diversas transformações na econômica, sociedade, cultura e política mundiais, aspectos que se estenderam e podem ser percebidas de forma significativa na atualidade. A revolução tecnológica digital do período ancorou a expansão do capital global, contribuindo para uma reorganização da sociedade industrial, com novas formas produção, circulação e consumo de mercadorias. E, de forma geral, teve grande empenho em redefinir também as formas de comunicação e convívio em sociedade, influenciando as relações entre as pessoas e delas com os produtos que produzem.

A partir dos anos 80-90, a sociedade começa a perceber a popularização da internet e a transformação do PC em um "computador coletivo" com conexão ao ciberespaço. No final do século XX, segundo Castells (1999), percebeu-se a necessidade da criação de um novo padrão tecnológico, o que ocorre principalmente pela nova configuração do processo de acumulação do capital, resultando na produção de, cada vez, mais produtos e serviços de características mais sofisticadas. $\mathrm{O}$ quadro fez com que se intensificasse a competição entre as empresas, baseada em diferenciais tecnológicos. Desta maneira, o espaço cibernético tem possibilitado que as pessoas imaginem e busquem informações e realizem a comunicação, dando ao ciberespaço certa onipresença.

No início dos anos 90, quando a internet é aberta para uso comercial, surge o $e$ commerce. Segundo Albertin (1999), o comércio eletrônico foi a realização de toda a cadeia de valor e processos de negócios em um ambiente eletrônico, por meio da aplicação de intensa tecnologia de informação e de comunicação, atendendo os objetivos de negócios solicitados pelas pessoas ou empresas. Com o surgimento do e-commerce, criaram-se condições que fizeram com que os usuários trocassem informações e realizassem transações financeiras e de negócios.

As lojas online trazem como vantagens a possibilidade de preços menores que os do comércio tradicional, com a diminuição de custos com salão de vendas, manutenção, funcionários, entre outros encargos. Trabalham fretes grátis, trazem ao encontro do consumidor lançamentos que ainda não estão disponíveis nas empresas com salão de vendas, além de uma série de diferenciais que só são possibilitados pela grande compra que a empresa efetua perante aos fornecedores. Esse aspecto é explicado pela ampla fatia de mercado que

DRd - Desenvolvimento Regional em debate (ISSNe 2237-9029) 
elas ocupam, possuindo flexibilização das barreiras territoriais e assim em contato com mais consumidores em diferentes locais.

Para Pavlou e Fygenson (2006), a experiência de compra pela internet permitiu a otimização do tempo de comparação dos preços, produtos e marcas, o que justificaria o crescimento do e-commerce. Porter (2001) afirma que a eficácia do e-commerce já foi provada nos resultados de vendas das empresas e da aceitação por parte dos consumidores que utilizaram esta forma de comércio. Há indicativos de que os consumidores aprovaram essa forma de venda (FELIPINI, 2012). Essa tendência iminente possibilita a comparação de preços por diversas ferramentas trazidas pela internet, fazendo com que a oferta, que antes era local, passasse a ser global, possibilitando o consumidor pesquisar preços. Segundo Reichheld e Schefter (2000), o e-commerce e a internet de modo geral tornaram a oferta mais transparente, facilitando a comparação de produtos e serviços, gerando maior preocupação com a concorrência de modo a garantir a continuidade do negócio.

No mercado atual, grande parte das empresas já não ignora mais a presença das possibilidades que a internet oferece. Para as empresas com forte vinculação territorial, os desafios desse tipo de comercialização ganharam outros contornos, inclusive exigindo readequações na cultura da organização, estudadas neste artigo a partir do caso das Lojas Eny, uma vez que encontram novos concorrentes inclusive em grandes organizações de varejo online caráter mundial, que entram com força nos mercados regionais.

\section{POSICIONAMENTO DE COMUNICAÇÃO}

O posicionamento de serviço ou de marca está inserido nas estratégias de marketing e de comunicação de uma organização; marketing e comunicação seguem o posicionamento. $\mathrm{O}$ posicionamento seria, para Kotler (2002), o lugar que o serviço ou a marca ocupa na mente dos consumidores potenciais; um conjunto complexo de percepções, impressões e sensações que os clientes mantêm em relação ao serviço ou a marca da organização.

Segundo Ries e Trout (2002), o termo "posicionamento" surgiu segunda metade do século XX. Na época, começou-se a perceber a importância da imagem e da boa reputação de uma empresa e desta forma o posicionamento passa a ser algo essencial para as organizações.

Posicionamento é um conceito complexo, com relação direta com a imagem da marca e com a identidade da marca de um produto ou organização. Além de estabelecer diferenciação competitiva com os concorrentes, o posicionamento envolve uma imagem clara sobre a marca, produto ou serviço, o que remete a sua identidade. Essa, por sua vez, é uma espécie de promessa da organização aos seus clientes (AAEKER, 1996). A promessa orienta os esforços e iniciativas da construção da imagem da marca ou produto junto aos consumidores. A identidade carrega o conjunto de características intransferíveis que identificam a marca e expõem a organização, tendo projeção direta na imagem pretendida pela empresa. E, por sua vez, a identidade auxilia na criação do posicionamento da organização, uma vez que o processo da identidade da marca está calcado nos recursos, processos, profissionais, modelo de gestão, entre outros aspectos da organização. É interessante que posicionamento e identidade estejam alinhados. 
O processo de construção do posicionamento da marca se completa no âmbito dos consumidores, na sua interação com a organização. Rocha e Christensen (1999) afirmam que o posicionamento da marca é desenvolvido pelos consumidores por meio da imagem que a marca representa nas suas mentes em relação a seus concorrentes,

Sendo assim, um processo de posicionamento precisa implementado pra que se efetive junto ao consumidor. O que ocorre por meio de estratégias em níveis diferentes de atuação. Segundo Aaker (1996), um planejamento pode ser estabelecido para diversos setores da economia ou atividades comerciais e ainda para marcas, organizações e até mesmo para linhas de produtos segmentadas dentro de uma própria organização, em consonância com um posicionamento geral da organização.

A construção do posicionamento teria uma dimensão operacional e outra estratégica (MUHLBACHER, 1994). Na operacional, o posicionamento é um conceito de comunicação em que os atributos da marca devem ser destacados na promoção da organização. Esta dimensão parte do princípio de que o posicionamento é também um conceito de comunicação, que serve como guia para as ações de comunicação. $O$ posicionamento aparece, nessa dimensão operacional, na política de produtos e nas definições relativas aos atributos que devem ser desenvolvidos e enfatizados. Já a dimensão estratégica dá conta do posicionamento como diretriz norteadora para a implementação do marketing.

Quando a empresa define um (novo) posicionamento, ou necessita (re)posicionar-se perante a penetração de um concorrente, o planejamento estratégico de comunicação é o caminho para se comunicar o que a empresa quer transmitir. A comunicação irá transmitir informação, ideias e outros da organização e que sejam de interesse do público. $\mathrm{O}$ planejamento estratégico, de forma geral, define o público e o que deve ser dito, o planejamento estratégico de comunicação define como isto deve ser dito, em que momento e de que forma.

O posicionamento parte de uma perspectiva interna e processual da organização, através de estratégias traçadas para alcançar seu objetivo de espaço no mercado (MONTE, 1998). Por isso, após se definir um posicionamento, utiliza-se do marketing a fim de alcançar a posição desejada no mercado, entendido como o conjunto das atividades humanas que têm por objetivo facilitar e consumar as relações de troca. $\mathrm{O}$ marketing permite o planejamento das ações da empresa, inclusive as de comunicação.

Para a definição das estratégias, é necessário pensar no planejamento. Kunsch (2003) acredita que o planejamento deve ser visto e pensado como um processo, que envolve o modo de pensar e questionar a organização para que, a partir disso, sejam tomadas as decisões necessárias, caracterizando-se assim como um planejamento estratégico, termo que tem sido adotado por empresas que pensam a organização inserida no mercado.

Portanto, o adequado é o posicionamento estar inserido nas estratégias de marketing das organizações e ser resultante de um planejamento (estratégico). As ações de comunicação, nesse entendimento, visam construir ou reforçar um posicionamento como lugar do produto, serviço ou marca na mente dos consumidores potenciais, sendo resultado de um planejamento e parte de uma estratégia de marketing. 


\section{LOJAS ENY NA DINÂMICA REGIONAL}

Santa Maria nasce de um acampamento demarcatório, no final do século XIX. A historiografia registra a presença de indígenas, assim como do local sendo passagem para as Missões Jesuíticas e rota de tropeiros que buscavam gado na Campanha gaúcha. Ainda no final do século XIX, recebe as primeiras linhas férreas, que vão tornar a cidade um grande entroncamento ferroviário de acesso a todo Rio Grande do Sul, por meio da Rede Ferroviária Federal, gerando com intenso fluxo de pessoas e de cargas. Como consequência, tem-se um salto na urbanização e no crescimento do comércio e dos serviços, particularidade territorial que vai marcá-la até a contemporaneidade (DEGRANDI, 2010).

Na primeira metade do século também se inicia o ensino superior na cidade, com algumas faculdades que, em 1960, integram-se na Universidade Federal de Santa Maria, o que atraiu para a cidade estudantes oriundos da metade oeste do Estado. O movimento segue até a atualidade, sendo que em 2015, a UFSM tinha 28.844 estudantes. Além do ensino, serviços ofertados pela Universidade, como o do maior hospital público do interior do Estado (dez mil internações ano), traz pessoas para Santa Maria (UFSM, 2015). O lugar de centro regional de ensino superior criado pela UFSM abriu mercado para outras instituições de natureza privada, existindo duas outras universidades privadas e quase uma dezena de centros de ensino.

Outra presença que marca Santa Maria é a militar. Vista geograficamente como estratégica na proteção de fronteiras, o uso militar do território fixou na cidade cerca de 20 unidades do Exército, Aeronáutica, Brigada Militar, Quartel do Corpo de Bombeiros, Policia Civil Estadual, Policia Federal, Policia Rodoviária Federal, assim hospitais, tribunais e o colégio militar. Em 2010, somente das Forças Armadas eram 10 mil militares (ASSEMBLEIA LEGISLATIVA, 2015). As instituições militares interagem diretamente com o cotidiano da cidade e têm importância fundamental na influência da formação sócio espacial (DEGRANDI, 2010).

De forma geral, este apanhado de fatores estimulou o crescimento do comércio. Atualmente, Santa Maria tem aproximadamente 240 mil habitantes, boa parte formada por funcionários públicos e privados dos setores de comércio e serviços, e uma população flutuante de estudantes de ensino superior. É o coração de uma região formada por 34 municípios, a Central, porém o público consumidor que a ela se dirige vem também de outras regiões, como Fronteira Oeste, Missões, Planalto e Vale do Rio Pardo, muito em função dos serviços de saúde e de educação, mas sua presença repercute no comércio.

Nesse contexto, a história das Lojas Eny se confundem com a da cidade, pois surge na esteira do desenvolvimento urbano do início do século $\mathrm{XX}$ e vai crescendo à media que a cidade e seu comércio se expande, sendo pioneira em muitas inovações, como a introdução de grandes vitrines, a colocação das primeiras lojas em galerias comerciais e em calçadão e os pontos de venda segmentados. Nas últimas décadas, segue acompanhando os movimentos de espacialidade do comércio da cidade, aderindo à presença em shoppings e, mais recentemente, a alterações na estrutura interna das lojas com a introdução de terminais eletrônicos e lojas de autoatendimentos. Por um lado, adere a mudanças, de outro, mantém certas características que

DRd - Desenvolvimento Regional em debate (ISSNe 2237-9029) 
a marcam, como a exclusividade de vendas em salão de vendas, sendo que o projeto de aderir ao $e$-commerce é uma realidade distante. (GERENTE, 2016) ${ }^{4}$.

\section{PROCEDIMENTOS METODOLÓGICOS}

O estudo foi desenvolvido durante os anos de 2014 e 2015. Teve natureza qualitativa, envolvendo pesquisa bibliográfica, e coleta de dados a campo, com pesquisa documental e entrevistas.

A pesquisa bibliográfica buscou a apropriação teórica referente aos estudos sobre território, região, globalização, comércio eletrônico e posicionamento de comunicação. Uma pesquisa bibliográfica tem o seu princípio, quando se encontra um problema a ser resolvido, para tanto uma resposta somente será encontrada após uma série de estudos e realizações sobre o tema (DUARTE, 2005).

A análise documental incorporou relatórios e materiais de comunicação da Eny, alguns obtidos junto aos gestores da empresa, outros coletados nos pontos de venda (materiais de divulgação e promoção) e outros capturados pela internet (site, página das lojas na rede social, notícias e publicidades). Documentos funcionam como um recurso utilizado no resgate da história de meios de comunicação, personagens, empresas ou períodos (MOREIRA, 2008).

As entrevistas de caráter semiestruturado foram realizadas com o Gerente Geral da empresa, com a Coordenadora de Comunicação e Marketing, e com o Social Media da Eny. Duarte (2004) afirma que, embora não haja obrigatoriedade do uso de entrevistas em pesquisa qualitativa, ela ainda é muito requisitada.

Por fim, os materiais foram analisados a partir da proposta de Ries e Trout (1989), que preveem três etapas para se compreender o posicionamento de comunicação de uma organização, que são verificar: a) o objetivo da estratégia de comunicação; b) o diferencial da estratégia de comunicação; c) a vantagem perante os concorrentes. Relativa à primeira etapa, analisou-se a estratégia comunicacional da Eny; na segunda, foram percebidas as ações de posicionamento; e na terceira, foram compreendidas as estratégias de comunicação, com vistas a chegar ao seu posicionamento de comunicação.

\section{POSICIONAMENTO ATUAL DAS LOJAS ENY}

A Eny Comercio de Calçados LTDA se organiza através de uma gerência familiar, com três principais membros intitulados gerentes, localizados em Santa Maria. Cada filial tem "gerente de loja". Na área de comunicação, há um departamento, em Santa Maria, constituído por uma relações públicas, um publicitário e um jornalista, com funções distintas, porém

\footnotetext{
${ }^{4}$ Os entrevistados para a pesquisa não serão identificados pelos seus nomes, mas pelos seus cargos.
} 
integradas. A coordenação está com a relações públicas, que gesta a área e faz a mediação dessa com os demais setores da empresa; o jornalista desenvolve a assessoria de imprensa (relações e produção de conteúdo informacional para a mídia) e o publicitário é responsável pelas mídias sociais (site, Instagran, Facebook da Eny). Uma agência de publicidade terceirizada produz as campanhas para Natal, Dia dos Pais, Dia das Mães e outras datas televisão.

A ameaça dos concorrentes online é uma preocupação da Eny. As entrevistas com os profissionais da comunicação e com o gerente, bem como os produtos de comunicação realizados, confirmam. Cliente informado sobre a concorrência e com pouco tempo para realizar a compra (presencial) são entraves recentes que a Eny tem que dar conta.

\begin{abstract}
A empresa sempre monitora e preocupa-se com todos os concorrentes, independente da modalidade de negócio. O que a Eny faz é treinar seus colaboradores, oferecer instalações adequadas, apresentar um mix variado de produtos modernos e com qualidade, zelar pela qualidade de seus serviços, oferecer condições atraentes de pagamentos aos clientes, para gerar o encantamento do cliente para que ele possa dar preferência ao nosso sistema de compra. (GERENTE, 2016)
\end{abstract}

O Gerente (2016) aponta que nos últimos anos a empresa sentiu mudanças nos hábitos de compra dos consumidores, o que a levou a tomar algumas atitudes, entre as quais, destaca: (a) realizar compras de estoque em menor quantidade e maior frequência para oferecer mais novidades ao consumidor; (b) ajustar os processos para cobrir qualquer preço de concorrente local, (c) aumentar a exposição interna de produtos como forma de facilitar a escolha e reduzir tempo de compra para o cliente; (d) inaugurar sua primeira loja de autoatendimento (em Santa Maria), visando agilizar a compra e dando autonomia ao consumidor. As estratégias já foram avaliadas e deram certo, conforme o entrevistado.

A inserção da Eny no e-commerce seria algo distante, na palavra do Gerente (2016), pois exigiria um maior capital para aquisição de espaço físico de estoque e também um maior investimento em produtos, que comporte esta demanda exigida pela internet, além da necessidade de montar um setor de tecnologia da informação com conhecimentos avançados, capazes de viabilizar o processo. Nessa linha, conforme o Social Media da Eny (2015), a estratégia é adaptar "a nossa realidade das cidades em que a empresa está presente para suprir a necessidade dos clientes".

Assim, a empresa buscou compensar a não possibilidade de vendas online adotando algumas práticas, entre as quais: (a) treinar seus funcionários para que eles percebam as tendências do consumidor sobre compra online; (b) oferecer instalações adequadas em um ambiente agradável e limpo; (c) apresentar uma oferta variada de produtos modernos e com qualidade; (d) zelar pela qualidade de seus serviços, desde o momento da compra até uma possível necessidade de troca do produto; (e) oferecer condições atraentes de pagamentos aos clientes. (GERENTE, 2016; COORDENADORA DE COMUNICAÇÃO, 2016; SOCIAL MEDIA, 2015). 
Figura 1 - Estrutura interna modernizada de uma da lojas.

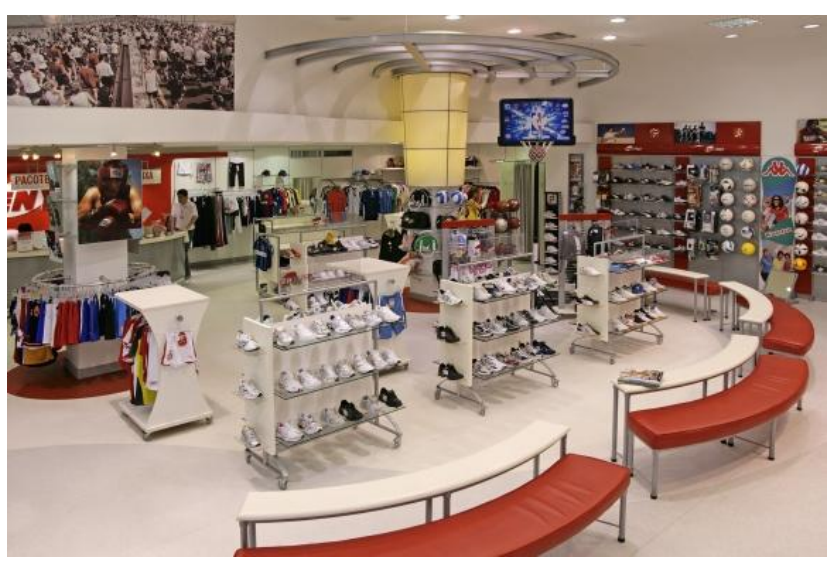

Fonte: http://eny.com.br

Segundo o Gerente, esses seriam os aspectos para que o consumidor perceba as vantagens no sistema "tradicional" de compra, adotado pela empresa nos mais de 90 anos. Os entrevistados afirmaram ainda que todos os materiais de comunicação da Eny buscam transmitir essas ideias e valores, que acabam por se traduzir no posicionamento (de comunicação) da empresa, baseado na relação de confiança e de transparência estabelecida entre empresa e cliente, firmada na tradição da Eny na região.

A coordenadora e relações públicas afirmar que a empresa Eny aposta na relação de quase um século com o consumidor de Santa Maria e seu entorno. A comunicação da Eny mantém um trabalho já feito há décadas e tem procurado intensificar as ações em: (a) realizar pesquisas de satisfação dos clientes periodicamente, colhida no interior das lojas; (b) disponibilizar "caixinha" da SAC (serviço de atendimento ao consumidor), como item obrigatório em todas as lojas; (c) não deixar o cliente sem resposta, quando essas solicitadas por meio dos canais de comunicação da empresa (COORDENADORA DE COMUNICAÇÃO, 2015). O setor passou por modificações há dois anos, com a troca da gestora, que implementou uma série de mudanças nas ações, as já apontadas, e mais a criação de ferramentas de comunicação pela internet, com página no Facebook, Instagran, WhatsApp, site, blog e Vitrine Virtual (COORDENADORA DE COMUNICAÇÃO, 2015; SOCIAL MEDIA, 2015).

Na sequência, as ações implementadas pela Eny e sua análise a partir da proposta de Ries e Trout (1989) de ver o objetivo da estratégia de comunicação, o diferencial da mesma e a vantagem perante os concorrentes:

a) Exposição de produtos e loja de autoatendimento: em 2014 a Eny inaugurou sua primeira loja de autoatendimento, em Santa Maria.

O que a estratégia visa? Aumento da exposição dos produtos nas lojas e permitir autonomia ao consumidor.

Qual o principal diferencial desta estratégia? A adaptação que a marca teve em modificar sua forma atual de exposição dos produtos e estilo de loja. A empresa com mais de 90 anos sempre foi conhecida por suas vitrines e vendedores atenciosos, no entanto, até então, 
o contato do consumidor com o produto se dava sempre pela mediação realizada por um funcionário.

Qual a principal vantagem perante os concorrentes? A forma inovadora na cidade de loja de exposição de produtos. Na relação com os concorrentes online, a Eny ofertou um serviço que trouxe algumas características do e-commerce.

Figura 2 - Loja de autoatendimento Eny

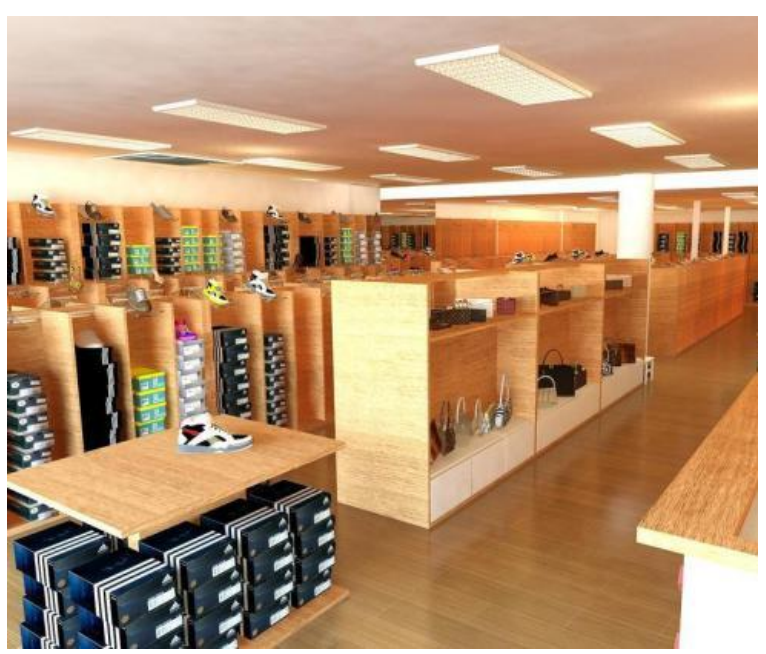

Fonte: http://diariodesantamaria.clicrbs.com.br/rs/economia-politica/noticia/2014/11/eny-calcados-inauguranova-loja-nesta-sexta-feira-4649792.html

b) Mudanças na oferta de produtos: a Eny modificou a forma de compra junto aos fornecedores, diminuindo a quantidade de produtos adquiridos em cada compra, realizando compras mais frequentemente e participando mais de feiras com o intuito de trazer lançamentos com mais frequência às lojas.

O que a estratégia visa? Possibilita ao cliente acesso a um maior número de lançamentos em menor tempo.

Qual o principal diferencial desta estratégia? Possibilitar a empresa oferecer tendências e novos lançamentos.

Qual a principal vantagem perante os concorrentes? A Eny é a única empresa do varejo local a participar de feiras. Em relação aos concorrentes online, essa medida aproxima a Eny de oferecer os produtos que os concorrentes oferecem, no mesmo espaço de tempo, com a possibilidade de pronta entrega.

c) Capacitação dos empregados: os entrevistados disseram que houve o diagnóstico que clientes iam às lojas experimentar calçados e depois realizavam as compras em lojas virtuais de outras empresas. A partir do conhecimento dessa prática, realizaram capacitações com os funcionários para buscarem reverter essa prática do 
consumidor, reforçando as vantagens da compra presencial. Ainda, foi investido na modernização das lojas para que o cliente tivesse um ambiente mais agradável para a compra.

O que a estratégia visa? Oferecer aos clientes uma estrutura de qualidade com profissionais dispostos a facilitar ao máximo o processo de compra e pós-compra dos produtos.

Qual o principal diferencial desta estratégia? Reforçar o posicionamento da empresa, de bom relacionamento com seu público, ancorado em relações de confiança e transparência.

Qual a principal vantagem perante os concorrentes? Diante tanto dos concorrentes locais, como online, o atendimento personalizado.

d) Pesquisas de satisfação dos clientes: as entrevistas demonstraram preocupação da direção em ter os retornos dos clientes sobre as lojas. Por outro lado, os clientes também encaminham muitas dúvidas através das redes sociais. Assim, o diálogo informal entre clientes, vendedores e gerentes das lojas, e também sugestões nas caixas de SAC localizadas no interior das lojas são instrumentos de grande valor para a empresa perceber a opinião de seu público.

O que a estratégia visa? Ter o cliente como um norteador de ações futuras.

Qual o principal diferencial desta estratégia? Possibilita ao cliente opinar, dá liberdade ao mesmo para manifestar suas insatisfações e satisfações perante à organização.

Qual a principal vantagem perante os concorrentes? A relação de liberdade para com a empresa, com pergunta ou crítica, e o compromisso de retorno por parte da empresa, surgem como um diferencial perante seus concorrentes.

Figura 3 - Caixa de pesquisa de satisfação dos clientes posicionada em loja.

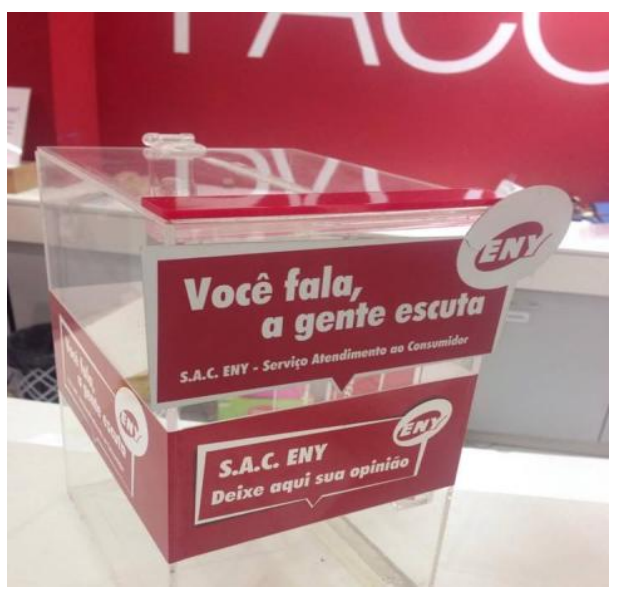

Fonte: Autores.

DRd - Desenvolvimento Regional em debate (ISSNe 2237-9029) 
e) Inserção em mídias da internet: a preocupação com as mídias na internet surgiu nos últimos quatro anos. Foi lançada uma plataforma virtual de exposição dos produtos, a Vitrine Virtual, e estabelecidos espaços nas redes sociais (página no Facebook, Instagran e WhatsApp), bem como presença com site e blog da Eny.

O que a estratégia visa? Ter a marca na internet e propiciar que o consumidor tenha contato com produtos, lançamentos e informações sobre os mesmos.

Qual o principal diferencial desta estratégia? Uma mudança cultural na Eny.

Qual a principal vantagem perante os concorrentes? Fornecer conteúdo na internet com a credibilidade da Eny.

Figura 4 - Post da página da Eny no Facebook.

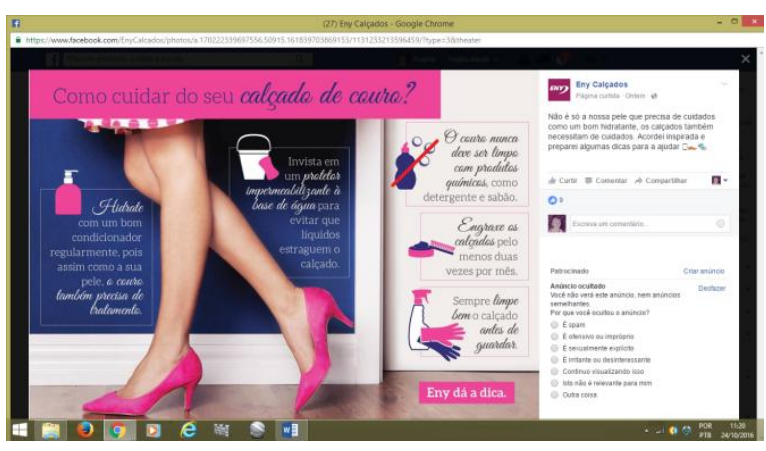

Fonte: https://www.facebook.com/EnyCalcados/

Figura 5 - Vitrine Virtual.

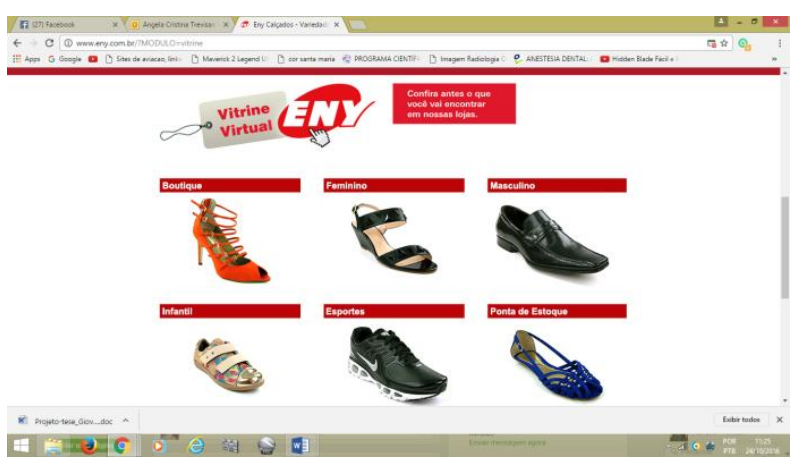

Fonte: http://www.eny.com.br/?MODULO=vitrine

Abaixo, o Quadro 1 traz uma síntese da análise da estratégia de comunicação com vistas a compreensão do posicionamento de comunicação da Eny. 
Quadro 1 - Esquema analítico a partir do modelo Ries e Trout (1989).

\begin{tabular}{|c|c|c|c|}
\hline $\begin{array}{l}\text { Estratégia de } \\
\text { comunicação }\end{array}$ & $\begin{array}{l}\text { Objetivo da } \\
\text { estratégia de } \\
\text { comunicação }\end{array}$ & $\begin{array}{l}\text { Diferencial da } \\
\text { estratégia }\end{array}$ & Vantagem perante concorrência \\
\hline $\begin{array}{l}\text { Exposição } \\
\text { produtos/loja } \\
\text { autoatendimento }\end{array}$ & $\begin{array}{l}\text { Aumento da } \\
\text { visibilidade e da } \\
\text { autonomia do } \\
\text { consumidor. }\end{array}$ & $\begin{array}{l}\text { Adaptação da } \\
\text { organização a nova } \\
\text { forma de expor produtos } \\
\text { e nova forma de venda. }\end{array}$ & $\begin{array}{l}\text { Uso de recursos do e-commerce } \\
\text { (autoatendimento) com manutenção } \\
\text { da loja física. }\end{array}$ \\
\hline $\begin{array}{l}\text { Mudança na oferta } \\
\text { dos produtos }\end{array}$ & $\begin{array}{l}\text { Acesso do cliente a } \\
\text { mais lançamentos. }\end{array}$ & $\begin{array}{l}\text { Eny oferece com mais } \\
\text { frequência tendências e } \\
\text { lançamentos. }\end{array}$ & $\begin{array}{l}\text { Mantém a loja física e o } \\
\text { atendimento personalizado com } \\
\text { maior e mais ágil oferta de } \\
\text { lançamentos. }\end{array}$ \\
\hline $\begin{array}{l}\text { Capacitação dos } \\
\text { empregados para } \\
\text { atendimento }\end{array}$ & $\begin{array}{l}\text { Capacitar } \\
\text { profissionais para } \\
\text { melhor } \\
\text { atendimento dos } \\
\text { clientes. }\end{array}$ & $\begin{array}{l}\text { Bom atendimento } \\
\text { correspondendo às novas } \\
\text { expectativas do } \\
\text { consumidor. }\end{array}$ & $\begin{array}{l}\text { Atendimento personalizado e } \\
\text { presencial. }\end{array}$ \\
\hline $\begin{array}{l}\text { Pesquisa de satisfação } \\
\text { dos clientes }\end{array}$ & $\begin{array}{l}\text { Ter o cliente como } \\
\text { norteador de ações. }\end{array}$ & $\begin{array}{l}\text { Maior compreensão do } \\
\text { comportamento do } \\
\text { consumidor. }\end{array}$ & $\begin{array}{l}\text { Possibilidade de opinar sobre a } \\
\text { organização e de obter o retorno a } \\
\text { partir de mecanismos mais diretos } \\
\text { do que as pesquisas feitas por } \\
\text { empresas virtuais. }\end{array}$ \\
\hline $\begin{array}{l}\text { Inserção em mídias } \\
\text { da internet (Vitrine } \\
\text { Virtual, página no } \\
\text { Facebook, Instagran e } \\
\text { WhatsApp, etc) }\end{array}$ & $\begin{array}{l}\text { Ter a marca na } \\
\text { internet e chegar } \\
\text { de forma virtual ao } \\
\text { consumidor. }\end{array}$ & $\begin{array}{l}\text { Mudança cultural da } \\
\text { organização. }\end{array}$ & $\begin{array}{l}\text { Oferecer conteúdo aos clientes pela } \\
\text { internet, semelhante aos } \\
\text { concorrentes do } \text { e-commerce, mas } \\
\text { com credibilidade da Eny. }\end{array}$ \\
\hline
\end{tabular}

Fonte: Elaborado pelos autores.

As ações apontadas fazem parte de estratégias de comunicação da Eny, que, como vista, resultam de percepções e adequações gerais da organização perante seu público. As ações de comunicação foram resultado também de um planejamento de comunicação, apontado pelos professionais e gestores e dão os indicativos do posicionamento de comunicação da organização. Viu-se que a Eny remodelou o setor de comunicação, reorientou as ações e mídias utilizadas e promoveu mudanças na forma de comunicar e no conteúdo alcançado ao público. Os caminhos vão ao encontro do que a maior parte dos autores sobre posicionamento de comunicação, planejamento e estratégia consultados para esta pesquisa apontam como sendo o adequado.

Do mesmo modo, chegou-se à conclusão que a Eny manteve seu posicionamento de comunicação tradicional, calcado numa relação de décadas estabelecida entre a organização e o consumidor, destacado pelos dirigentes como tendo base na confiança e na transparência. Assim, a Eny não mudou seu posicionamento, mudou práticas, reforçando um posicionamento que já tinha, procurando valorizar o que a diferenciava do comércio virtual e empreendido por empresas de fora do território, sem vínculos estabelecidos de certa permanência com o consumidor. Percebeu-se que a Eny buscou elementos para reforçar seu posicionamento na longa relação estabelecida com o cliente, com uma marca consolidada.

Os resultados da pesquisa reiteram o que dizem os autores quando acusam a necessidade de coerência entre posicionamento e ações estratégicas, bem como a concepção de um posicionamento ancorado não apenas na diferenciação competitiva com a concorrência, mas também na imagem que a marca já tem na mente dos consumidores, na identidade da

DRd - Desenvolvimento Regional em debate (ISSNe 2237-9029) 
marca. Os atributos enfatizados (confiança e transparência) existiam antes das mudanças dos últimos anos, no entanto novas ações foram feitas para reforça-los e divulgá-los.

\section{CONSIDERAÇÕES FINAIS}

A possibilidade de compras online tem se apresentando como um desafio para as empresas tradicionais em pontos de venda e com forte vinculação territorial. Segundo Rowley (2002) este método de compra alcançou proporções mundiais e fez com que as empresas que atuavam apenas através de canais tradicionais tivessem a se adaptar cada vez mais ao ecommerce como um canal complementar. O e-commerce foi em pouco tempo incorporado por uma grande parcela da população brasileira e não pôde ser ignorado pelo comércio tradicional.

No caso da empresa Eny Comércio de Calçados LTDA, a pesquisa indicou a existência de preocupação por parte dos dirigentes e dos profissionais de comunicação, bem como de uma reação da organização nos últimos anos buscando destacar as qualidades tradicionais da empresa e da marca, seja em ações concretas nos pontos de venda, seja na comunicação da empresa.

As ações de comunicação elaboradas pela Eny que, conforme visto, reforçaram o posicionamento já existente junto aos clientes, indicam uma modernização da organização, considerando pesquisas de opinião, nova estética e recursos de venda nas lojas e entrada na comunicação via internet. Por outro lado, essa atualização das formas de se comunicar com seu cliente foi ancorada em valores tradicionais da Eny, que são a confiança e a transparência. A Eny usou de novos meios para projetar uma imagem relacionada à identidade de organização com tradição e confiança no comércio regional, mas que se moderniza seguindo a tendência dos tempo.

Assim, as Lojas Eny buscam se manter no mercado e ter vantagens perante a concorrência, especialmente a virtual, reforçando o que as caracterizam, adequando as estratégias de vendas e de comunicação aos interesses do consumidor e com ferramentas que até então não utilizadas.

As empresas fazem parte dos territórios e os compõem, os transformam em recursos para si e ao mesmo tempo são estratégias desses espaços para sobrevivência (SANTOS, 2006). A quase centenária Eny se confunde com a história do comércio da região Central do Rio Grande do Sul, integra a particularidade do território, que teve no comércio um caminho de desenvolvimento não só econômico, mas social. Muitas inovações no setor foram introduzidas pela Eny, afinadas com o processo de urbanização de Santa Maria. Outras, como as analisadas neste artigo, foram ajustes para manter sua permanência no território, ações reativas para sobrevivência da organização diante de novos desafios. 


\section{REFERÊNCIAS}

AAKER, David. Criando e administrando marcas de sucesso. São Paulo: Futura, 1996.

; SHANSBY J. Gary. Positioning your product. Business Horizons, Greenwich, v. 25, n. 3, p. 56-62, maio/jun. 1982.

ALBERTIN, Alberto Luiz. Comércio eletrônico: modelo, aspectos e contribuições de sua aplicação. São Paulo: Atlas. 1999.

CASTELLS, Manoel. A sociedade em rede: a era da informação: economia, sociedade e cultura. São Paulo: Paz e Terra, 1999. v. 1.

DEGRANDI, José Odim. Horizontalidades e verticalidades no desenvolvimento territorial de Santa Maria - RS. In.: BIENAL DEL COLOQUIO DE TRANSFORMACIONES

TERRITORIALES; XVIII. Anales... Buenos Aires, 2010. Disponível em:

<https://www.nescon.medicina.ufmg.br/biblioteca/imagem/2514.pdf>. Acesso em: 09 ago. 2015.

DUARTE, Jorge. Entrevista em profundidade. In: DUARTE, Jorge; BARROS, Antonio (org.). Métodos e técnicas de pesquisa em comunicação. São Paulo: Atlas, 2005.

E-COMMERCE. Disponível em: 〈http://www.e-commerce.org.br>. Acesso em: 9 ago. 2015.

ENTREVISTA semi-estruturada com a Coordenadora Geral de Comunicação e Marketing da empresa Eny Comércio de Calçados LTDA, realizada dia 28 dez. 2015.

ENTREVISTA semi-estruturada com o Gerente Geral da empresa Eny Comércio de Calçados LTDA, realizada dia 11 jan. 2016.

ENTREVISTA semi-estruturada com o profissional de Social Media da empresa Eny Comércio de Calçados LTDA, realizada dia 21 dez. 2015.

ENY CALÇADOS INAUGURA NOVA LOJA NESTA SEXTA-FEIRA. Disponível em: $<$ http://diariodesantamaria.clicrbs.com.br/rs/economia-politica/noticia/2014/11/eny-calcadosinaugura-nova-loja-nesta-sexta-feira-4649792.html>. Acesso em: nov. 2014.

ENY. Blog da Eny Calçados. Disponível em <http://enycalcados.blogspot.com.br/2016/10/opcoes-de-presentes-de-r-1990-r-100.html>. Acesso em: 24 out. 2016.

Página no Facebook. Disponível em: <https://www.facebook.com/EnyCalcados/>. Acesso em: 24 out. 2016. out. 2016.

Site da Eny Calçados. Disponível em: <http://www.eny.com.br/>. Acesso em: 24

FELIPINI, D.. Ecommerce 11 anos: uma explosão de crescimento. 2012. Disponível em: <www.e-commerce.org/artigos/ecommerce-11 anos.php>. Acesso em: 24 out. 2016. 
FLORES, Murilo. A identidade cultural do território como base de estratégias de desenvolvimento: uma visão do estado da arte. RIMISP, 2006. Disponível em: $<$ http://indicadores.fecam.org.br/uploads/28/arquivos/4069_FLORES_M_Identidade_Territor ial_como_Base_as_Estrategias_Desenvolvimento.pdf>. Acesso em: 15 maio 2015.

HAESBAERT, Rogerio. Regional-global: dilemas da região e da regionalização na geografia contemporânea. Rio de Janeiro: Bertrand Brasil, 2010.

KOTLER, Philip. Administração de marketing. São Paulo: Prentice Hall, 2000.

KUNSCH, Margarida Maria Krohling. Planejamento de relações públicas na comunicação integrada. 4.ed. São Paulo: Editora Summus, 2003.

MONTE, Edmar Ferreira. A estrutura e o funcionamento da propaganda ao nível estratégico. Caderno de Pesquisa em administração, São Paulo, v. 1 n. 7, $2^{\circ}$ trimestre 1998.

MOREIRA, Sonia Virgínia. Análise documental como método e como técnica. In: BARROS, Antônio; DUARTE, Jorge (orgs). Métodos e técnicas de pesquisa em comunicação. 2.ed. São Paulo: Atlas, 2008.

MÜHLBACHER, Hans. MIPS: Managing industrial positioning strategies. Industrial Marketing Manegement. New York, 1994.

ORTIZ, Renato. Mundialização e cultura. São Paulo: Brasiliense, 1994.

PAVLOU, Paul A,; FYGENSON, Mendel. Understanding and predicting eletronic commerce adoption: na extension of the theory of planned behavior. Mis Quarterly, v, 30, n. 1, p. 115143, 2006.

PORTER, Michael E. Estrategy and the internet. Harvard Bussines Review. 2012.

Cambridge, Massachusetts, 2001.

REICHHEL, F.; SCHEFTER, P. E-Loyalty. Harvard Business. Massachusetts, 2000.

Review (July/August)

RIES, Al; TROUT, Jack. Posicionamento: a batalha por sua mente. 20.ed. São Paulo: Makron Books, 2002.

1989.

Posicionamento: como a mídia faz sua cabeça. 2.ed. São Paulo: Pioneira,

RIO GRANDE DO SUL. ASSEMBLEIA LEGISLATIVA. Disponível em:

<http://www.al.rs.gov.br/site/>. Acesso em: 5 out. 2015.

ROCHA, Ângela; CHRISTENSEN, Carl. Marketing: teoria e prática no Brasil. São Paulo: Atlas, 1999.

ROWLEY, J. Synergy and strategy in e-business. Marketing Intelligence \& Planning, v. 20, n. 4, p. 215-222, 2002. 
SANTOS, Milton. A natureza do espaço: técnica e tempo, razão e emoção. 4.ed. 2. reimpr. São Paulo: Editora da Universidade de São Paulo, 2006.

UFSM. Disponível em: <www.ufsm.br>. Acesso em 5 out. 2015.

UPSHAW, Lynn. B. Building brand identity: a strategy for success in a hostile marketplace. New York: John Wiley \& Sons, 1999.

Artigo recebido em: 20/05/2016

Artigo aprovado em: 09/11/2016 